\title{
Advanced Sarcoma of the Extremity
}

National Cancer Institute

\section{Source}

National Cancer Institute. Advanced Sarcoma of the Extremity. NCI Thesaurus. Code C155649.

A sarcoma of the soft tissues or bones of the upper or lower extremity that has spread extensively to other anatomic sites or is no longer responding to treatment. 